\title{
Home visits for Parkinson disease - a window into a murky situation
}

\author{
Indu Subramanian ${ }^{1,2}$ \\ ${ }^{1}$ Department of Neurology, Geffen School of Medicine, UCLA, Los Angeles, CA, USA; ${ }^{2}$ Department of Neurology, West Los Angeles Veterans \\ Administration, LA, CA, USA \\ Correspondence to: Indu Subramanian, MD. Department of Neurology, David Geffen School of Medicine, UCLA, 710 Westwood Blvd, Los Angeles, \\ CA 90095, USA. Email: ISubramanian@mednet.ucla.edu. \\ Provenance and Peer Review: This article was commissioned by the Editorial Office, Annals of Palliative Medicine. The article did not undergo external \\ peer review. \\ Comment on: Fleisher JE, Klostermann EC, Hess SP, et al. Interdisciplinary palliative care for people with advanced Parkinson's disease: a view from \\ the home. Ann Palliat Med 2020;9:S80-9.
}

Submitted Oct 31, 2019. Accepted for publication Nov 25, 2019.

doi: 10.21037/apm.2019.11.26

View this article at: http://dx.doi.org/10.21037/apm.2019.11.26

Increasingly immobile Parkinson disease (PD) patients may become home-bound or bed-bound, representing a major obstacle to their optimal care. Evidence regarding best practices in this murky situation is scant. The study by Fleisher and colleagues provides new insights into the issues faced by home-bound PD patients, and examines new potential evaluation and treatment approaches to improve their management.

Many health care providers develop a close rapport with patients with $\mathrm{PD}$ and their loved ones. We serve as a shoulder to cry on or a hand to hold for decades of their $\mathrm{PD}$ trajectory. Once the patient is no longer able to come to clinic, we lose the ability to interact with these patients and to truly grasp what they and their caregivers are dealing with as their disease advances. Sometimes we can place a phone call to check in with the patient. Using advanced technology, it is currently possible to perform a telehealth visit to give just a glimpse or snapshot into the reality of the home environment (1). However, home visits, during which a provider can sort through medications and walk alongside a patient through the halls of their home, may be the only way to truly be able to appreciate their safety issues and barriers to care. Though these types of comprehensive home visits have been studied in other complex conditions (2-6), Dr. Fleisher and her team have made the first attempt to examine the challenges and benefits of approaches to home care in $\mathrm{PD}$ patients.

The long-term care of PD patients can be very complex.
Certain medications that are used to treat issues in the advanced PD patient such as antipsychotics can actually worsen the PD symptoms dramatically. Hence, continued expert care involvement with a movement disorder specialist is critical. The fact that only one-third of residents of longterm care facilities with PD continue to receive outpatient neurologist care is alarming (7). In the pilot phase of this study, patients were visited by a movement disorders specialist, nurse and social-worker. Interventions included identifying motor and non- motor symptoms, medication errors, home safety issues and unmet psychosocial needs. These interventions are all very meaningful and can keep a home-bound patient out of the hospital or emergency room. Thus, even though the intervention seems cost-prohibitive and inefficient, utilizing large amounts of time and effort by highly qualified team members, it may in fact lead to cost savings due to prevention of acute hospital -based care (8). Of note, there were $52 \%$ women in the first phase of the study. This is a disproportionate number of women in Phase 1 of the study, given the fact that PD occurs more commonly in men. This large number of women, raises some interesting possibilities. Are women more likely to be home bound and alone once their disease advances, i.e., they do not have husbands or children that care for them vs men with PD? Are more women likely to live into late stages of PD since women live longer than men?

The second phase of the study (IN-HOME PD) included telehealth visits by the movement disorder specialist and 
visits $2-4$ with the social worker via telehealth. It is a smart and necessary choice to include. Since the first phase of the study required so many providers to travel at each visit, it would be extremely difficult to replicate this model in any other center. The use of an in-home nurse to complete medication reconciliation and home safety evaluations is very practical since home nurses are often ordered through home- health for PD patients and can be reimbursed through insurance models that already exist. The inhome social worker for visit one is also helpful to identify social issues and can start a conversation on advanced care directives. Continued use of the multi-disciplinary team that includes the movement disorder specialist before making the plan of care is crucial as these subspecialists are uniquely equipped to understand the nuanced complexity of this advanced phase of PD. The main outcomes of this study, is that quality of life was preserved even as UPDRS scores worsened by 12 points in a very advance population of PD patients. The demographics of the populations studied in the two phases are quite striking. The first phase included $70 \%$ of patients in the most immobile group of PD $(\mathrm{H}+$ $\mathrm{Y}$ stage 4 and 5 ). The second phase included $40 \%$ of PD patients with dementia.

The authors illustrate case studies with truly remarkable outcomes that highlight the benefits of this in-depth team -based approach in the lives of two complex, advanced PD patients. Any one such case can make this kind of seemingly tough work very rewarding.

The palliative care ramifications of this intervention are significant. The goal of allowing a patient to die in their home is laudable. Honoring a patient's wishes is what makes our job as physicians rewarding. By keeping people out of institutions at critical time-points in their illness, it becomes much more likely that the PD patient will die in their home when the time comes (6). Onset of hallucinations and dementia are two such turning points in a patient's illness (9). If a patient can stay in their own home with home care, it can lead to higher patient centered outcomes and quality of life. The ability to discuss advance directives with the patient in the comfort of their own home is extremely important (10). Patients are often much more at ease in their own home rather than a sterile clinic surrounding. The fact that advanced directives were addressed in $90 \%$ of patients in this study, is a testament to how well the home-setting works for this crucial conversation since it is a much higher rate than what normally transpires in an office setting.

Further information that is intriguing that can be gleaned from a home visit include the following: (I) the use of complementary and alternative (CAM) therapies can be explored, Peering into a medicine cabinet or drawers in a bathroom may lead to information on supplements that the patient may not consider part of their Parkinson therapy. It has been estimated that at least $60 \%$ of $\mathrm{PD}$ patients use some form of CAM therapy. Most of their therapies are not being shared with their medical providers (11); (II) exploration of impulse control issues such as hoarding, hobbyism or over-shopping. By visiting the home, the provider can uncover these sorts of behavioral issues that may be otherwise hidden in a clinical visit; (III) decoding why a patient freezes or falls in certain locations in their home by physically being able to watch a patient walk in their everyday home environment; (IV) examining diet and nutrition can be much more accurate, by looking into a patient's refrigerator or through their kitchen equipment to give the provider a hands-on view of how the patient will actually be able to prepare healthy meals. Additionally, walking through a patient's neighborhood can give invaluable information on whether there is access to fresh fruits and vegetables or if they are surrounded by only fast food places; (V) gaining a better understanding of the social isolation a patient may face is invaluable. By meeting the patient where they actually live and seeing their surroundings, the health care team can get a clear picture of the true social interactions that the patient has and the reallife safety issues including crime and social disparities the patient confronts.

Social isolation and loneliness have been identified as risk factors in general aging populations for increased morbidity and mortality. In fact, social isolation has been linked to worse health outcomes than smoking cigarettes in aging populations at large (12). It is hard to fully understand the depth of social issues in a brief office visit and even when questioned, patients may not be willing to be fully honest about their living conditions. Investigating barriers such as uneven sidewalks, icy roads and crime-filled neighborhoods can give the provider a real-time look at why patients and their care-givers do not want to leave their homes. The benefits on social isolation and loneliness with this type of team-based intervention should not be underestimated. Seeing a friendly face or their long-trusted doctor can work wonders for the psyche of a lonely bed-bound patient or a burnt out care-giver. There is likely benefit to the emotional well-being of the health care team as well with knowing that their beloved patient continues to receive high-level care and that their wishes are being respected and quality of life 
is preserved even into the end-of-life timeframe.

Though not easily translatable to real life circumstances, this study by Fleisher et al shows that the use of home care team in advanced PD populations is invaluable and leads to preserved quality of life despite worsened motor symptoms. The home care visit affords a unique window into the world of the advancing PD patient and their caregiver and opens the door for future research possibilities and scope for interventions.

\section{Acknowledgments}

Funding: None.

\section{Footnote}

Conflicts of Interest: The author has no conflicts of interest to declare.

Etbical Statement: The author is accountable for all aspects of the work in ensuring that questions related to the accuracy or integrity of any part of the work are appropriately investigated and resolved.

Open Access Statement: This is an Open Access article distributed in accordance with the Creative Commons Attribution-NonCommercial-NoDerivs 4.0 International License (CC BY-NC-ND 4.0), which permits the noncommercial replication and distribution of the article with the strict proviso that no changes or edits are made and the original work is properly cited (including links to both the formal publication through the relevant DOI and the license). See: https://creativecommons.org/licenses/by-nc-nd/4.0/.

\section{References}

1. Achey M, Aldred JL, Aljehani N, et al. The past, present, and future of telemedicine for Parkinson's disease. Mov Disord 2014;29:871-83.

2. Edes T, Kinosian B, Vuckovic NH, et al. Better access, quality, and cost for clinically complex veterans with home- based primary care. J Am Geriatr Soc 2014;62:1954-61.

3. Kono A, Kanaya Y, Tsumura C, et al. Effects of preventive home visits on health care costs for ambulatory frail elders: a randomized controlled trial. Aging Clin Exp Res 2013;25:575-81.

4. Boult C, Green AF, Boult LB, et al. Successful models of comprehensive care for older adults with chronic conditions: evidence for the Institute of Medicine's "retooling for an aging America" report. J Am Geriatr Soc 2009;57:2328-37.

5. DeCherrie LV, Soriano T, Hayashi J. Home-based primary care: a needed primary-care model for vulnerable populations. Mt Sinai J Med 2012;79:425-32.

6. Tanuseputro P, Beach S, Chalifoux M, et al. Associations between physician home visits for the dying and place of death: A population-based retrospective cohort study. PLoS One 2018;13:e0191322.

7. Safarpour D, Thibault DP, DeSanto CL, et al. Nursing home and end-of-life care in Parkinson disease. Neurology 2015;85:413-9.

8. Koay L, Rose J, Abdelhafiz AH. Factors that lead to hospitalisation in patients with Parkinson disease-A systematic review. Int J Clin Pract 2018. doi: 10.1111/ ijcp. 13039.

9. Aarsland D, Larsen JP, Tandberg E, et al. Predictors of nursing home placement in Parkinson's disease: a population-based, prospective study. J Am Geriatr Soc 2000;48:938-42.

10. Kluger BM, Persenaire MJ, Holden SK, et al. Implementation issues relevant to outpatient neurology palliative care. Ann Palliat Med 2018;7:339-48.

11. Bega D, Zadikoff C. Complementary \&amp; alternative management of Parkinson's disease: an evidence-based review of eastern influenced practices. J Mov Disord 2014;7:57-66.

12. Holt-Lunstad J. Why Social Relationships Are Important for Physical Health: A Systems Approach to Understanding and Modifying Risk and Protection. Annu Rev Psychol 2018;69:437-58.
Cite this article as: Subramanian I. Home visits for Parkinson disease-a window into a murky situation. Ann Palliat Med 2020;9(2):141-143. doi: 10.21037/apm.2019.11.26 